Adıyaman Üni. Sağlık Bilimleri Derg, 2016; 2(3):334- 347.

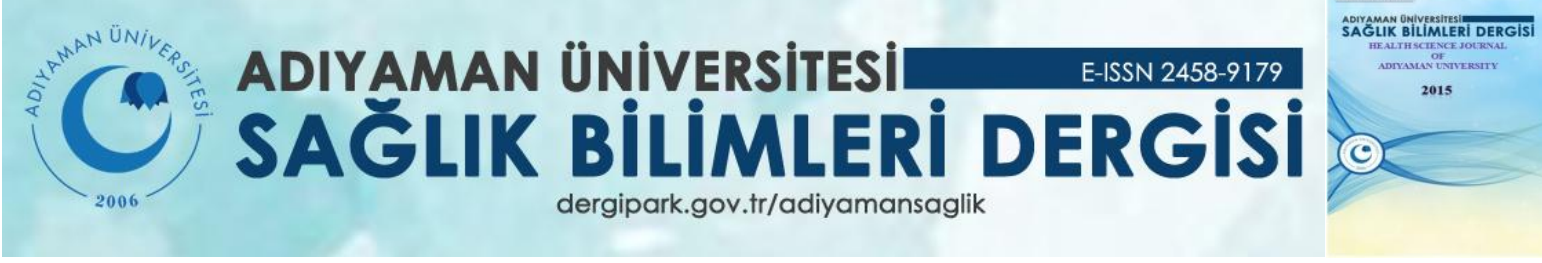

Araştırma/Research

\title{
Derin Anemi Nedeniyle Hastanede Yatan İnfant Hastaların Etiyolojik Açıdan İncelenmesi
}

\author{
Fatih İŞLEYEN ${ }^{1}$, Mehmet Tekin ${ }^{1}$,Çapan KONCA ${ }^{1}$, \\ ${ }^{1}$ Adıyaman Üniversitesi, Tıp Fakültesi Çocuk Sağlığı ve Hastalıkları Ana Bilim Dalı
}

\section{ÖZET}

Amaç: Anemi dünyadaki önemli sağlık problemlerinden birisidir. Bu çalışmada derin anemi nedeniyle hastanede yatan sütçocuğu olgularının anemi etiyolojisi açısından incelenmesini amaçladık.

Gereç ve Yöntem: Derin anemi nedeniyle hastanede yatan 1 ay-24 ay arasındaki hastaların dosyaları geriye dönük olarak incelendi. Hastaların yaş, cinsiyet, ağırlık ve sosyoekonomik durum gibi demografik verileri ile laboratuvar sonuçları kaydedildi.

Bulgular: Çalışmaya dahil edilen 34 olgunun 25'i $(\% 73,6)$ erkek, 9'u $(\% 26,4)$ kız idi. Hastaların yaş ortalaması $11,25 \pm 6,02$ ay idi. Yirmi hasta $(\% 58,8)$ demir eksikliği anemisi (DEA), dokuz hasta $(\%$ 26,5) megaloblastik anemi, üç hasta $(\% 8,8)$ hemolitik anemi, bir hasta $(\% 2,9)$ herediter sferositoz ve bir hasta $(\% 2,9)$ talasemi major tanisi ald1. Ayrica 21 hastada $(\%$ 61,7) taşikardi, 14 hastada (\% 41,1) mezokardiyak odakta sistolik üfürüm saptandı. Olguların 27'sinde (\% 79,4) kalp yetmezliği bulguları saptanması üzerine kan transfüzyonu yapıldı.

Sonuç: Çalışmamızda derin aneminin en sık nedeni olarak DEA ve ikinci sırada B12 eksikliğine bağlı megaloblastik anemi saptandı. Bulgularımız besinsel eksikliklerin düzeltilmesinin ve süt çocukluğu döneminde uygulanan demir proflaksisinin derin anemi gelişimini önlemede etkili olabileceğini desteklemektedir.

Anahtar kelimeler: Beslenme bozukluğu, derin anemi, sosyoekonomik düzey, süt çocuğu,

Yazışmadan Sorumlu Yazar

DOI: 10.30569/adiyamansaglik.389504

Mehmet Tekin

Adıyaman Üniversitesi, Tıp Fakültesi Çocuk Sağlı̆̆ı ve Hastalıkları Ana Bilim Dalı, Adıyaman

Tel : +90 05327699846

Email: drmehmettekin@hotmail.com

\begin{tabular}{ll}
\hline Geliş Tarihi: & $\mathbf{0 2 . 0 2 . 2 0 1 8}$ \\
\hline Kabul Tarihi: & $\mathbf{1 7 . 0 2 . 2 0 1 8}$
\end{tabular}




\section{Etiological Investigation of the Inpatient Infants due to Severe Anemia}

\section{SUMMARY}

Aim: Anemia is one of the major health problems in the world. In this study, we aimed to investigate the etiology of anemia in the inpatient infants due to severe anemia.

Material and methods: The records of the hospitalized patients aged 1 to 24 months due to severe anemia were retrospectively reviewed. Demographic data such as age, gender, weight and socioeconomic status of the patients and laboratory results were recorded.

Results: Twenty-five of the 34 cases $(73.6 \%)$ were male and 9 (26.4\%) were female. The mean age of the patients was $11.25 \pm 6.02$ months. Twelve patients $(58.8 \%)$ had iron deficiency anemia (DEA), nine patients $(26.5 \%)$ had megaloblastic anemia, three patients $(8.8 \%)$ had hemolytic anemia, one patient had hereditary spherocytosis and one patient $(2.9 \%)$ had thalassemia major. There were also tachycardia in 21 patients $(61.7 \%)$ and systolic murmur in mesocardiac focus in 14 patients $(41.1 \%)$. Blood transfusion was performed to 27 (79.4\%) cases which detected signs of heart failure.

Conclusion: In our study, DEA was the most common cause of severe anemia and megaloblastic anemia due to B12 deficiency in second place. Our findings support that the correction of nutritional deficiencies and the iron prophylaxis applied during infancy may be effective in preventing the development of severe anemia.

Key words: Infant, malnutrition, severe anemia, socioeconomic status 


\section{Giriş}

Anemi; hemoglobin (hb), hematokrit (htc) veya eritrosit değerlerinin yaşa ve cinse göre normal ortalama değerlerinin iki standart sapma altında olması olarak tanımlanır (1). Anemiler ağırlık derecesine göre üç gruba ayrılır. Dünya Sağlık Örgütü hafif, orta ve derin anemi sınır değerlerini 2011 yılında yayınlamıştır (2). Hb değerlerinin 1 ay-59 ay arası çocuklarda $7 \mathrm{gr} / \mathrm{dl}$ 'nin altında, diğer yaş gruplarında ise $8 \mathrm{gr} / \mathrm{dl}$ 'nin altında olması derin anemi olarak tanımlanmıştır.

Derin anemi, gelişme çağında olan çocuklarda nadir rastlanmayan bir durumdur (3). Beslenme yetersizliği veya bozukluğu, fakirlik, enfeksiyonlar ve bunlara ek olarak sağllk hizmetlerinden faydalanma olanaklarını az olması gibi durumlar hem derin anemiye neden olmakta hem de buna bağlı mortaliteyi arttırmaktadır (3). Dünya Sağlık Örgütü’nün anemiyi önleme konusundaki önerisi demir ve folik asit alımını arttırmaktır. Ancak demir eksikliği ve folik asit eksikliği tanıları dışındaki hastalarda bu yaklaşım mortaliteyi arttırabilir. Derin anemili hastalarda kan transfüzyonu hayat kurtarıcı olabilir (4). Kan transfüzyonu öncesinde tanıyı koymak ve tanıya uygun tedavi stratejisini belirlemek büyük önem taşımaktadır. Kan sayımı, periferik yayma ve diğer laboratuvar değerleri ile günlük çalışmalarda tanı ortaya konmaktadır.

$\mathrm{Bu}$ çalışmanın amacı, sütçocuğu kliniğimizde yatan derin anemili hastalarda altta yatan nedenlerin ortaya konması, aneminin ağırlık derecesine göre laboratuvar değerlerinin kıyaslanması ve tanıların belirlenmesidir. 


\section{Materyal ve Metot}

Çalışmamızda, 1 Ocak 2014 ile 31 Aralık 2015 tarihleri arasında Adıyaman Üniversitesi Tıp Fakültesi Çocuk Sağlığı ve Hastalıkları Anabilim Dalı Süt Çocuğu Servisinde derin anemi tanısı ile yatan 34 hastanın dosyaları geriye dönük olarak incelendi.

$\mathrm{Hb}$ değeri 7 gr/dl'nin altında olan, 1-24 ay arasındaki derin anemili olgular çalışmaya dahil edildi. Hb 7 gr/dl'nin üstünde olan hastalar, 2 yaşın üzerindeki hastalar ve daha önce talasemi major tanısı alıp düzenli aralıklarla eritrosit transfüzyonu yapılan takipli hastalar çalışma dışı bırakıldı.

Olguların yaş, cinsiyet, ağırlık, sosyoekonomik düzeyi ve demir damlası kullanım öyküsü gibi demografik verileri ile hb, htc, eritrosit sayısı (RBC), ortalama eritrosit hacmi (MCV), eritrosit dağılım hacmi (RDW), ortalama eritrosit hemoglobin konsantrasyonu (MCHC), lökosit, tombosit, Mentzer indeksi, demir, total demir bağlama kapasitesi (TDBK), transferrin satürasyonu, ferritin, retikülosit, direkt coombs, B12, folat, üre, kreatinin, aspartat aminotransferaz (AST), alanin aminotransferaz (ALT), laktat dehidrogenaz (LDH), indirekt bilirubin, $\mathrm{HbA2}$, HbF ve periferik yayma gibi laboratuvar sonuçları kaydedildi.

Demir eksikliği anemisi (DEA) kriterleri olarak; ortalama eritrosit hacmi (MCV) değerinin yaşa göre normal değerlerin iki standart sapma altında olması ile birlikte, serum ferritin değerinin $12 \mu \mathrm{g} / \mathrm{ml}$ altında olması, eritrosit dağ 11 ım hacminin (RDW) >\%15 olması ve serum demir bağlama kapasitesinin $480 \mu \mathrm{g} / \mathrm{ml}$ üstünde olması kabul edildi (5).

Megaloblastik anemi tanıs1, vitamin B12 düzeyinin $193 \mathrm{pg} / \mathrm{ml}$ altında olması, folik asit düzeyinin $3 \mathrm{ng} / \mathrm{mL}$ altında olması ve periferik yaymada megaloblastik değişikliklerin olması ile konuldu (6). 
Periferik yaymada parçalanmış eritrosit, çekirdekli eritrosit ve gözyaşı hücrelerinin görülmesi, retikülosit sayısı, LDH ve indirekt hemoglobin düzeylerinde artış saptanması hemolitik anemi lehine değerlendirildi (7). İmmün ve immün olmayan hemolitik anemiyi ayırt etmek amaciyla direkt coombs bakıld1.

Hastalar hemoglobin değerine göre 2 gruba ayrıldı. Hemoglobin 6 gr/dl altında olanlar grup 1, hemoglobin 6 gr/dl üstünde olanlar grup 2 olarak adlandırıldı.

Hastaların tümünde kanlar venöz yoldan alındı. Tam kanlar ethylenediaminetetraacetic acid içeren tüplere alınarak en geç bir saat içerinde laboratuvara gönderildi ve Cell-Dyn Ruby (Abbott Laboratories Product of Singapore) cihazında otomatik olarak çalışıldı. Biyokimyasal parametreler Architect c8000 Processing Module (Abbott Laboratories Manufactered in Japan) cihazı ile vitamin B12 ve folik asit düzeyi ise Unicel DxI 800 Access İmmunoassay System (Beckman Coulter, Inc. Made in USA) cihazı ile ölçüldü. Hemoglobin elekroforezi Bio-Rad D-10 Hemoglobin Testing System (Made in France) cihazında çalışıldı.

\section{İstatistiksel analiz}

İstatistiksel analizler için SPSS versiyon 23.0 (SPSS Inc. Chicago, IL, USA) programı kullanıldı. Kategorik verileri karşılaştırmak amacıyla Ki-kare ve Fisher's exact testi kullanıldı. Verilerin normal dağılım gösterip göstermediğini belirlemek için Kolmogorov-Smirnov testi yapıldı. Parametrik dağılım gösteren sürekli verilerin karşılaştırılması için Bağımsı İki Örneklem $t$ testi kullanıldı ve sonuçlar mean \pm SD olarak verildi. Nonparametrik dağılım gösteren sürekli verilerin karşılaştırılması için Man-Witney U testi kullanıldı ve sonuçlar median (minimum-maksimum) olarak verildi. $\mathrm{P}<0,05$ olan değerler istatistiksel olarak anlamlı kabul edildi. 


\section{Bulgular}

Derin anemi saptanan 40 hastanın dosyaları tarandı. Beta talasemi majör tanısıyla takipli olan ve düzenli transfüzyon tedavisi alan dört hasta ile daha önce akut lenfoblastik lösemi tanısı almış iki hasta çalışma dışı bırakıldı. Sonuç olarak çalışmaya toplam 34 hasta alındı. Olguların $25(\% 73,6)$ 'i erkek, $9(\% 26,4)$ 'u kız idi. Olguların yaş ortalaması $11.25 \pm 6,02$ ay (1,5-23 ay) idi.

Etiyolojik incelemede; $20(\% 58,8)$ hastada demir eksikliği anemisi, dokuz $(\% 26,5)$ hastada megaloblastik anemi, üç $(\% 8,8)$ hastada hemolitik anemi, bir $(\% 2,9)$ hastada herediter sferositoz ve bir $(\% 2,9)$ hastada talasemi major tespit edildi (Tablo 1).

Tablo 1. Hastaların anemi etiyolojisine göre dağılımı.

\begin{tabular}{|c|c|c|c|}
\hline & \multicolumn{2}{|c|}{ Cinsiyet } & \multirow[b]{2}{*}{$\begin{array}{l}\text { Total sayı } \\
\text { (yüzde) }\end{array}$} \\
\hline & Kız & Erkek & \\
\hline Demir eksikliği anemisi & $4(\% 11,8)$ & $16(\% 47)$ & $20(\% 58,8)$ \\
\hline $\begin{array}{l}\text { Vitamin B12 eksikliğine bağlı } \\
\text { megaloblastik anemi }\end{array}$ & $4(\% 11,8)$ & $4(\% 11,8)$ & $8(\% 23,6)$ \\
\hline Hemolitik anemi & - & $3(\% 8,8)$ & $3(\% 8,8)$ \\
\hline $\begin{array}{l}\text { Folat eksikliğine bağlı megaloblastik } \\
\text { anemi }\end{array}$ & - & $1(\% 2,9)$ & $1(\% 2,9)$ \\
\hline Talasemi major & $1(\% 2,9)$ & - & $1(\% 2,9)$ \\
\hline Herediter sferositoz & - & $1(\% 2,9)$ & $1(\% 2,9)$ \\
\hline Toplam & $9(\% 26,4)$ & $25(\% 73,6)$ & $34(\% 100)$ \\
\hline
\end{tabular}

Hemoglobin değeri 6 gr/dl'nin altındaki hastalar birinci grup, hemoglobin değeri 6 gr/dl ve üstünde olanlar ikinci grup olarak adlandırıldı. Birinci gruptaki hastaların 10’u 
$(\% 83,3)$ erkek, 2'si $(\% 16,7)$ kı idi. İkinci gruptaki hastaların 15'i $(\% 68,1)$ erkek, 7'si $(\% 31,9) \mathrm{k} ı$ idi. İki grup arasında cinsiyet açısından anlamlı farklılık saptanmadı $(\mathrm{p}=0,354)$.

Tablo 2. Anemi ağırlığına göre tanı dağılımı

\begin{tabular}{lcc}
\hline & Birinci grup & İkinci grup \\
& $(\mathbf{H b}<\mathbf{6}$ gr/dl $)$ & $(\mathbf{H b}>\mathbf{6 g r} / \mathbf{d l})$ \\
\hline Demir eksikliği anemisi & $4(\% 33,3)$ & $16(\%$ 72,7) \\
B12 eksikliğine bağlı megaloblastik anemi & $4(\% 33,3)$ & $4(\% 18,1)$ \\
Hemolitik anemi & $2(\% 16,6)$ & $1(\% 4,5)$ \\
Folat eksikliğine bağlı megaloblastik anemi & $1(\% 8,3)$ & - \\
Talasemi major & - & $1(\% 4,5)$ \\
Herediter sferositoz & $1(\% 8,3)$ & - \\
Toplam & $12(\% 100)$ & $22(\% 100)$ \\
\hline p=0,104 & &
\end{tabular}

İki grup anemi etiyolojisi açısından kıyaslandığında, birinci gruptaki beş hastada $(\% 41,6)$ megaloblastik anemi, dört hastada $(\% 33,3)$ demir eksikliği anemisi, iki hastada $(\% 16,6)$ hemolitik anemi ve bir hastada $(\% 8,3)$ herediter sferositoz saptand1 (Tablo 2). İkinci grupta ise 16 hastada $(\% 72,7)$ demir eksikliği anemisi, dört hastada $(\% 18,1)$ megaloblastik anemi, bir hastada $(\% 4,5)$ hemolitik anemi ev bir hastada $(\% 4,5)$ talasemi major saptand (Şekil 1). İki grup arasında tanı dağılımı açısından anlamlı fark saptanmadı ( $\mathrm{p}=0,104)$. 


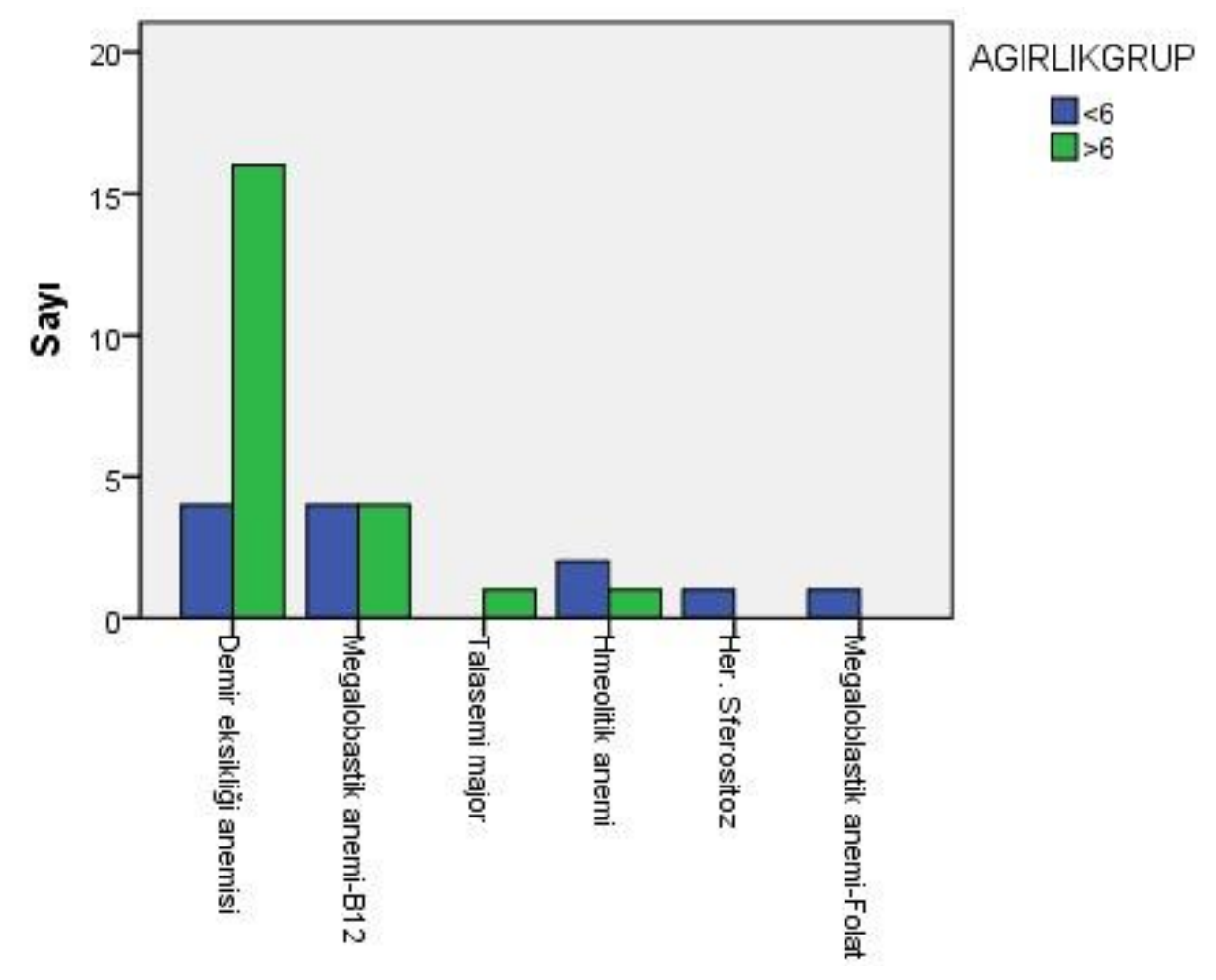

Şekil 1. Anemi ağırlığına göre tanı dağılımı.

Gruplar laboratuvar değerlerine göre kıyaslandığında, iki grup arasında MCV, MCHC, lökosit, trombosit, TDBK, ferritin, B12 düzeyleri açısından anlamlı fark saptanmadı (Tablo 3). RDW, demir düzeyi ve retikülosit sayısı ikinci grupta birinci gruba kıyasla anlamlı düzeyde düşük saptandı (sırasıyla $p=0,040, p=0,011$ ve $p=0,006$ ).

Hemoglobin elektroforezi değerlendirildiğinde bir hastada $(\% 2,9)$ talasemi major ile uyumlu sonuçlar elde edildi. Direkt coombs tüm hastalarda negatif bulundu.

B12 eksiksiliğine bağlı megaloblastik anemili sekiz hastanın ikisinde (\%25) bisitopeni ve ikisinde (\%25) pansitopeni saptandi. 
Tablo 3. Anemi ağırlığına göre grupların laboratuvar değerleri açısından karşılaştırılması.

\begin{tabular}{|c|c|c|c|}
\hline & $\begin{array}{l}\text { Birinci grup } \\
(\mathrm{Hb}<6 \mathrm{~g} / \mathrm{dl})\end{array}$ & $\begin{array}{l}\text { İkinci grup } \\
\text { (Hb >6 g/dl) }\end{array}$ & $\mathbf{p}$ \\
\hline MCV (fl) & $85,5(45-101)^{\mathrm{a}}$ & $59,5(47-108)$ & 0,263 \\
\hline MCHC(gr/dl) & $29,4 \pm 4,2^{\mathrm{b}}$ & $28,9 \pm 3,2$ & 0,719 \\
\hline RDW (\%) & $20,4 \pm 9,7^{\mathrm{b}}$ & $15,2 \pm 4,4$ & $0,040 *$ \\
\hline Lökosit $(/ \mu L)$ & $12069 \pm 7007^{b}$ & $11476 \pm 6455$ & 0,805 \\
\hline Trombosit $\left(\times 10^{3} / \mathrm{mm}^{3}\right)$ & $279491 \pm 119097^{\mathrm{b}}$ & $353509 \pm 172233$ & 0,196 \\
\hline $\operatorname{Demir}(\mu \mathrm{g} / \mathrm{dL})$ & $30,0(8-271)^{\mathrm{a}}$ & $18,5(5-123)$ & $0,011 *$ \\
\hline TDBK ( $\mu \mathrm{g} / \mathrm{dL})$ & $236,1 \pm 158^{\mathrm{b}}$ & $277,2 \pm 146,3$ & 0,453 \\
\hline Transferrin Sat.(\%) & $78,1 \pm 189,6^{\mathrm{a}}$ & $18,4 \pm 30,3$ & 0,153 \\
\hline Ferritin (ng/mL) & $24,5(1,4-443)^{\mathrm{a}}$ & $8,5(3,4-226)$ & 0,110 \\
\hline B12 (pg/dL) & $175,3 \pm 88,2^{\mathrm{b}}$ & $254,7 \pm 183,9$ & 0,170 \\
\hline Retikülosit (\%) & $6,5 \pm 7,6^{\mathrm{b}}$ & $1,6 \pm 1,5$ & $0,006 *$ \\
\hline
\end{tabular}

MCV, ortalama eritrosit hacmi; MCHC, ortalama eritrosit hemoglobin konsantrasyonu; RDW, eritrosit dağılım hacmi; TDBK, total demir bağlama kapasitesi; ${ }^{a}$, median (minimum-maksimum); ${ }^{b}$, mean $\pm \mathrm{SD} ;{ }^{*} \mathrm{p}<0,05$

Hastalarda en sık DEA saptanmış olup, bu hastaların 16'sında profilaktik demir tedavisinin hiç kullanılmadığı, dört hastada ise düzensiz ya da düşük dozda demir kullanıldığ1 öğrenildi. Tüm olguların sosyoekonomik düzeylerinin düşük olduğu gözlendi.

Fizik muayenede hastaların hepsinde cilt solukluğu görüldü. Ayrıca 21 hastada $(\% 61,7)$ taşikardi, 14 hastada $(\% 41,1)$ mezokardiyak odakta sistolik üfürüm saptandı. Olguların 27'sinde $(\% 79,4)$ kalp yetmezliği bulguları saptanması üzerine kan transfüzyonu yapild1. 


\section{Tartışma}

Derin anemi, dünyada önemli bir sağlık sorunu olmaya devam etmektedir. Büyüme dönemindeki çocuklarda derin anemi, nadir rastlanmayan bir durumdur $(3,5)$. Derin aneminin sıklığını fakirlik, malnütrisyon, enfeksiyonlar ve sağlık hizmetlerinden faydalanma olanağının az olması gibi sosyoekonomik faktörler belirlemektedir (8).

DEA çocuklardaki genel anemi ve derin aneminin en sık sebebidir. Demir eksikliği, büyüme çağında artmış olan demir ihtiyacının karşılanamaması nedeniyle özellikle süt çocukluğu döneminde sık görülür. Demir eksikliği anemisinin sıklığı süt çocuklarında inek sütü kullanımının kısıtlanması ve mamalara yapılan demir takviyesi ile 1970 yılından bu yana azalmakla birlikte günümüzde halen en sık görülen anemi olarak karşımıza çıkmaktadır. Süt çocukluğu döneminde demir eksikliği anemisinin, kognitif ve motor fonksiyonlarda gerilik oluşumuna neden olduğu kanıtlanmış olup bu çalışmalar demir eksikliği tedavisinin önemini ortaya çıkarmaktadır (9-12).

Çalışmamızda 34 derin anemili olgu ele alındı. Anemi ayırıcı tanısına göre değerlendirildiğinde; 20 hastada $(\% 58,8)$ DEA, dokuz hastada $(\% 26,5)$ megaloblastik anemi, üç hastada $(\% 8,8)$ hemolitik anemi, bir hastada $(\% 2,9)$ herediter sferositoz ve bir hastada $(\% 2,9)$ talasemi major tespit edildi. Ülkemizde Elazı̆̆'da yapılan bir çalışmada derin aneminin nedenleri, DEA ilk sırada olmak üzere malign hastalıklar ve hemolitik anemi olarak saptanmış olup bizim çalışmamızda da derin aneminin en sık nedeni olarak DEA tespit edilmiştir (9).

Erzurum ilinde yapılan çalışmada derin anemili hastalar içinde DEA olan hastaların \%86,5'sında sosyoekonomik düzeyin düşük olduğu bildirilmiştir (10). Çalışmamızda da hastaların büyük çoğunluğunun sosyoekonomik düzeylerinin düşük olduğu gözlendi. Ayrıca 
ebeveynler tarafından proflaktik demir tedavisinin düzenli olarak uygulanmadı̆̆ı saptandı. Sosyoekonomik düzeyin düşük olması, demir profilaksisinin düzenli verilmemesi ve beslenme bozukluklarının derin anemiye neden olduğunu düşünüyoruz.

Hindistan'da derin anemisi olan 40 hastada yapılan bir çalışmada \%42,5 ile en sık neden olarak megaloblastik anemi saptanmış, bunu takip eden aplastik anemi $(\% 27,5)$ ve DEA (\%15) izlemiştir. DEA çocuklarda en sık rastlanan derin anemi tipi olsa da, megaloblastik anemi ve aplastik anemi tanılarının atlanmaması gerektiği vurgulanmıştır (11). Hindistan'daki bu sonuç dini ve sosyoekonomik nedenlerle yeterli hayvansal protein tüketilmemesine bağlanmıştır. Çalışmamızda vitamin B12 eksikliğine anemi ikinci sıklıkta görülmekte olup sosyoekonomik düzeyin düşük olmasına bağlı olarak et tüketiminin az olmasına bağlı olabileceği düşünülmüştür.

$\mathrm{Bu}$ çalışmalar doğrultusunda derin anemi etiyolojisinin ülkeden ülkeye ve bölgeden bölgeye farklılık gösterdiğini görmekteyiz. Gelişmekte olan ülkelerde demir eksikliği anemisi, derin aneminin en sik nedeni olsa da megaloblastik anemi, aplastik anemi ve endemik bölgelerde HIV ve malaria enfeksiyonları da derin anemi etiyolojisinde önemli yer tutmaktadir (13).

Derin anemili hastaların tedavisinde eritrosit transfüzyonu önemli bir yer tutmaktadır. Hemoglobin değeri 7 gr/dl'nin altına düşmedikçe dokulara oksijen taşınması bozulmamaktadır. Hemoglobin düzeyinden ziyade doku perfüzyonunun korunmasında normovoleminin sağlanması önemlidir. Derin anemi tedavisinde yaşa göre transfüzyon için hemoglobin cutoff değeri değişse de çoğunlukla hemoglobini $7 \mathrm{gr} / \mathrm{dl}$ üstünde olup, stabil olan çocuklarda transfüzyon endike değildir. Fakat ani kan kaybı, yetmezlik bulgularının gelişmesi durumunda $8 \mathrm{gr} / \mathrm{dl}$ üstünde hemoglobin değerlerinde de eritrosit süspansiyonu verilebileceği 
bildirilmektedir (14). DEA hastalarında ise yetmezlik bulguları gelişmedikçe hb $4 \mathrm{~g} / \mathrm{dl}$ 'nin altına düşmedikçe transfüzyon önerilmemektedir (4). Kılıçaslan ve ark derin anemi nedeniyle yatırılan 28 hastanın 13'ünde $(\% 46,4)$ kalp yetmezliği bulguları nedeniyle eritrosit transfüzyonu yapıldığını bildirmişlerdir (15). Çalışmamızda da hastaların 27'sine $(\% 79,4)$ yetmezlik bulguları olması nedeniyle eritrosit transfüzyonu yapıldı. DEA olan hastalara demir replasman tedavisi verildi. Demir replasman tedavisinin derin demir eksikliğini önlemede rolü büyük olup kan transfüzyonuna olan ihtiyacı azaltmaktadır

Süt çocukluğu döneminde pansitopeni ile başvuran hastalarda B12 vitamin düzeyi bakılması önem arz etmektedir. Yüksel ve ark vitamin B12 eksikliği olan hastaların \% 19,4’ünde pansitopeni saptadıklarını bildirmişlerdir (16). Çalışmamızda vitamin B12 eksikliğine bağlı megaloblastik anemi saptanan hastaların \% 25'inde pansitopeni saptandı. Vitamin B12 eksikliği olan hastalara intramuskuler kobalamin, folik asit eksikliği olan hastalara ise oral folik asit tedavisi başlandı.

Sosyoekonomik düzeyi düşük olan ve besin kaynaklarına yeterince ulaşamayan toplumlarda nutrisyonel anemilerin daha sık görüldüğü, dolayısıyla derin anemi saptanan hastalarda öncelikle demir, vitamin B12 ve folik asit düzeylerinin bakılmasının önemli olduğu bildirilmiştir (17-19). Çalışmamızda da derin anemilerin çoğunlukla nutrisyonel bozukluklardan kaynaklandığı ve bu ailelerin sosyoekonomik düzeylerinin düşük olduğu gözlendi.

Sonuç olarak hastalarımızda derin aneminin en sık nedeni olarak DEA ve ikinci sırada B12 eksikliğine bağlı megaloblastik anemi saptandı. Bulgularımız besinsel eksikliklerin düzeltilmesinin ve süt çocukluğu döneminde demir proflasisinin derin anemi gelişimini 
önlemede etkili olabileceğini desteklemektedir. Ülke çapında yapılacak geniş çaplı çalışmalarla bulgularımızın desteklenmesi gerekmektedir.

\section{Kaynaklar}

1. Sullivan KM, Mei Z, Grummer-Strawn L, Parvanta I. Haemoglobin adjustments to define anaemia. Trop Med Int Health 2008;13(10):1267-71.

2. WHO's Certified[ Internet]. Vitamin and Mineral Nutrition Information System [Internet] Switzerland: Hemoglobin concentrations for the diagnosis of anemia and assesment of severity. C 2000-1. Availabel from: http://www.who.int/vmnis/indicators/haemoglobin.

3. Hensbrock MB, Jonker F, Bates I. Severe acquired anaemia in Africa: new concepts. Br J Haematol 2011;154:690-95.

4. Sloniewsky D. Anemia and transfusion in critically ill pediatric patients: a review of etiology, management, and outcomes. Crit Care Clin 2013;29(2):301-17.

5. Özdemir N. Iron deficiency anemia from diagnosis to treatment in children. Turk Pediatri Ars 2015;50(1):11-9.

6. Baumgartner MR. Vitamin-responsive disorders: cobalamin, folate, biotin, vitamins B1 and E. Handb Clin Neurol 2013;113:1799-810.

7. Loiselle K, Lee JL, Szulczewski L, Drake S, Crosby LE, Pai AL. Systematic and Meta-Analytic Review: Medication Adherence Among Pediatric Patients With Sickle Cell Disease. J Pediatr Psychol 2016;41(4):406-18.

8. Pasricha SR, Drakesmith H. Iron Deficiency Anemia: Problems in Diagnosis and Prevention at the Population Level. Hematol Oncol Clin North Am 2016;30(2):309-25.

9. Güvenç H, Aygün AD, Soylu F, Kocabay K. Çocukluk döneminde derin anemi etyolojisinde demir eksikliğinin önemi. MN Pediatri 1994;1:149-52.

10. Şimşek Ö, Büyükavcı M, Kaya MD, Akdağ R, Karakelleoğlu C. Orta derecede rakımda yaşayan Erzurum ve pediatri polikliniğine başvuran 6 ay- 6 yaş arasındaki çocuklarda anemi prevalansı ve etyolojik faktörler. Zeynep Kamil Bülteni 2005;36:33-8.

11. Kapil U, Tyagi M. Etiology of severe anemia amongst adolescent children. Indian J Pediatr 2012;79:401-2.

12. Baker RD, Greer FR. Diagnosis and prevention of iron deficiency and ron deficiency anemia in infants and young children. Pediatrics 2010;126:1040-1050. 
13. Charles CV, Summerlee AJ, Dewey CE. Anemia in Cambodia: prevalence, etiology and research needs. Asia Pac J Clin Nutr 2012;21(2):171-81.

14. Reeve K, Jones H, Hatrey R. Transfüsion guidelines in children:1. Anaesth Intensive Care 2014;13:20-23.

15. Kılıçaslan Ö, Yıldırmak ZY, Urgancı N. Derin anemi nedeni ile çocuk kliniğine yatırılıp demir eksikliği tanısı alan olguların değerlendirilmesi. Ş.E.E.A.H. Tıp Bültesi 2014;48:234-8.

16. Yüksel Ş, Uslan İ, Acartürk G, Çölbay M, Karaman Ö, Maralcan M, Demir S. A Retrospective Evaluation of Patients with Vitamin B12 Deficiency. Medical Journal of Bakırköy 2006;2:126-9.

17. Stevens GA, Finucane MM, De-Regil LM, Paciorek CJ, Flaxman SR, Branca F, Peña-Rosas JP, Bhutta ZA, Ezzati M; Nutrition Impact Model Study Group (Anaemia). Global, regional, and national trends in haemoglobin concentration and prevelence of total and severe anaemia in children and pregnant and nonpregnant women for 1995-2011: a systematic analysis of population-representative data. Lancet Glob Health 2013;1(1):16-25.

18. Patra S, Pemde HK, Singh V, Chandra J, Dutta A. Profile of adolescents with severe anemia admitted in a tertiary care hospital in Northern India. Indian J Pediatr 2011;78(7):863-5.

19. Alvarez-Uria G, Naik PK, Midde M, Yalla PS, Pakam R. Prevalence and severity of anaemia stratified by age and gender in Rural India. Anemia 2014;2014:176182. 